\title{
Inovação em Tecnologias de Checkout Aplicada como Vantagem Competitiva e Redução das Filas em Supermercados
}

\author{
Emerson Eduardo da Silva ${ }^{\mathrm{I}}$ (1) 0000-0002-7860-5443 \\ Universidade Federal de São Paulo - São Paulo - São Paulo - Brasil
}

\begin{abstract}
Resumo: O presente artigo buscou verificar se existe uma relação clara entre inovação no checkout, vantagem competitiva e redução das filas no segmento de supermercados na cidade de São Paulo. O trabalho se inicia com uma fundamentação teórica sobre a importância da constante inovação em serviços e sobre o conceito de vantagem competitiva e, por fim, apresenta a metodologia de pesquisa e as técnicas de análise utilizadas. Utilizamos a metodologia de pesquisa qualitativa. Os dados foram coletados por meio de observação não-participante (contato indireto do pesquisador) junto a uma amostra não probabilística por conveniência de 40 supermercados da cidade de São Paulo, nas regiões norte, sul, leste e oeste. Utilizamos a técnica de análise descritiva nos dados. Ao todo, identificamos três fatores: eficiência, tempo de espera e desistência, como os mais relevantes.
\end{abstract}

Palavras-chave: Supermercados, Checkout, Vantagem Competitiva, Inovação, Redução das Filas.

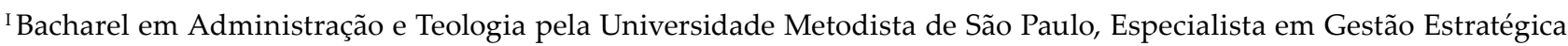
de Negócios pela Universidade Presbiteriana Mackenzie, Graduando em Design Educacional pela Universidade Federal de São Paulo e Representante do Conselho Regional de Administração de São Paulo no município de São Paulo. E-mail: emerson.eduardo@unifesp.br.
} 


\title{
Innovation in Checkout Technologies Applied as a Competitive Advantage and Reduced Queues in Supermarkets
}

\begin{abstract}
This article sought to verify whether there is a relationship between innovation at checkout, competitive advantage, and the reduction of queues in the Supermarkets segment in the city of São Paulo. The work begins with a theoretical foundation on the importance of constant innovation in services and the concept of competitive advantage. Finally, it presents the research methodology and analysis techniques used. We chose to use a Qualitative research methodology. Data were collected through non-participant observation (indirect contact of the researcher) with a non-probabilistic sample for convenience with 40 supermarkets in the city of São Paulo, in the north, south, east and west regions. Data analysis was performed using the descriptive analysis technique. Altogether, three factors were identified: efficiency, waiting time, and withdrawal.
\end{abstract}

Keywords: Supermarkets, Checkout, Competitive Advantage, Innovation, Queue Reduction.

\section{Innovación en Tecnologías Checkout Aplicadas como Ventaja Competitiva y Reducción de Colas en Supermercados}

Resúmen: Este artículo buscó verificar si existe relación entre innovación en la caja, ventaja competitiva y reducción de colas en el segmento de supermercados en la ciudad de São Paulo. El trabajo parte de una base teórica sobre la importancia de la innovación constante en los servicios y sobre el concepto de ventaja competitiva, para finalmente presentar una metodología de investigación y cómo se utilizan las técnicas de análisis. Elegimos utilizar una metodología de investigación cualitativa. Los datos fueron recolectados mediante observación no participante (contacto indirecto del investigador) de una muestra no probabilística por conveniencia con 40 supermercados en la ciudad de São Paulo, en las regiones Norte, Sur, Este y Oeste. El análisis de los datos se realizó mediante la técnica de análisis descriptivo. En total, se identificaron tres factores: eficiencia, tiempo de espera y retiro, como los más relevantes.

Palabras clave: Supermercados; Caja; Ventaja Competitiva; Innovación; Reducción de Colas. 


\section{Introdução}

O objetivo deste artigo foi verificar se existe uma relação entre a inovação na etapa de checkout a vantagem competitiva e a redução das filas nas redes de supermercados da cidade de São Paulo. Sua importância está atrelada ao fato do aumento do Paulistano utilizar os supermercados para compras em poucas unidades, menos de dez itens, segundo a última Pesquisa "Tendências do Consumidor em Supermercados 2018/2019" da Associação Paulista de Supermercados - APAS, conduzida pelo IBOPE Inteligência. Tal pesquisa revelou as características e o aumento das compras semanais das famílias brasileiras e dados sobre a quantidade de produtos comprados.

É apontado, nesta pesquisa, mudanças no comportamento das famílias brasileiras em relação às idas aos supermercados, visto que as compras mensais vêm perdendo espaço para as compras semanais, sendo que essa mudança de consumo ocorreu principalmente pela entrada cada vez maior da mulher no mercado de trabalho, atrelado a ofertas e promoções semanais dos supermercados, e ao aproveitamento no trajeto de ida e/ou volta ao emprego, e neste percurso, realizarem suas compras.

A causa de estudo deste trabalho é o segmento de supermercados na capital Paulista. Os mesmos surgiram nos Estados Unidos na década de 1930, e diferentemente do que ocorreu nos Estados Unidos, onde o supermercado surgiu como resposta à crise econômica em uma tentativa de diminuir custos, o Brasil passava por um período de grande desenvolvimento durante a década de 1950, apesar de apresentar diversos problemas sociais e econômicos (CYRILLO, 1987). E, quase para completar um século, já está mais que consolidado como um mercado de máxima importância no dia a dia das pessoas.

O segmento de supermercados na capital Paulista apresenta um panorama de alta competitividade, à altura dos grandes centros metropolitanos, com franquias de menores tamanhos físicos, pertencentes a grandes varejistas e Key Accounts. Essa dimensão competitiva influencia todo o segmento de supermercados, pois os competidores carecem de um maior profissionalismo e padronização das suas operações e inovações nos serviços, para que possam competir de acordo com o novo padrão de exigência dos clientes, atrelado ao potencial do consumo e concorrência dos mesmos. Empresas de supermercados passam a investir mais em modernização de seu atendimento, criando atrativos de serviços para idas a suas lojas, mas que necessitam de sistemas de checkout mais eficientes.

Além destas justificativas, verificou-se uma busca constante da inovação em serviços visto a lacuna existente quando se trata de sua relação com a vantagem competitiva ao setor de supermercados. Diante desta lacuna, em maio de 2018, a Associação Paulista de Supermercados (APAS) realizou um Hackathon para fomentar soluções para melhorar o stress ocasionado pelas filas nos supermercados, em sua tradicional feira anual a "APAS Show", o maior evento supermercadista do mundo, que ocorre todos os anos na cidade de São Paulo e busca integrar toda a cadeia de abastecimento. A entidade tem em torno de 1.500 associados, que somam mais de quatro mil lojas. 


\section{Problema de Pesquisa e Objetivo}

A presente pesquisa busca responder à seguinte pergunta: a inovação nas filas de checkout é fonte de vantagem competitiva e redução das filas no setor de Supermercados na cidade de São Paulo? O objetivo geral é verificar se há uma relação entre a inovação no modo do pagamento das compras e qual a vantagem competitiva nesta etapa operacional para os supermercados da cidade de São Paulo. Como objetivos específicos têm-se: identificar se há processo de inovação em serviços no setor de supermercados; e identificar quais são os benefícios com a inovação no checkout para o referido setor.

No momento da escolha do supermercado, o consumidor se depara com vários fatores que influenciam em sua decisão, tais como: localização; formas de pagamento; disponibilidade de estacionamento; qualidade de atendimento; variedade de produtos; preços; ofertas; entre outros. Para Nisczak (2015), apud Rinaldi et al. (2009), "os fatores que mais influenciam o cliente no momento de escolha do estabelecimento são: o preço e o tamanho das filas".

Pesquisa conduzida por New Vision Inc., em colaboração com a Universidade do Estado de São Petersburg, constatou que nada mais irrita os consumidores do que filas em supermercados (NCR CORPORATION, 2014). Com isso, muitos dos supermercados estão apostando em softwares e serviços automatizados com o propósito de oferecer ao cliente: aumento da eficiência, da produtividade e da competividade (PAINEL LOGÍSTICO, 2017).

\section{Revisão Bibliográfica}

\subsection{Inovação em Serviços}

Inovação é definida, conforme Pavitt (1984, s/p), "como um produto ou processo produtivo novo ou melhor, usado ou comercializado com sucesso por uma organização". E de acordo com o mesmo, é reconhecido que os incentivos da inovação, principalmente tecnológica, são de suma importância para o desenvolvimento econômico mundial.

Drucker (1987) afirma que a inovação é o instrumento específico dos empreendedores, o processo pelo qual eles exploram a mudança como uma oportunidade para um negócio diferente ou um serviço diferente. Inovação não é um lampejo de genialidade, é trabalho duro, que deve ser organizado como uma parte regular de cada unidade dentro da empresa e de cada nível gerencial. Inovação é o ato de atribuir novas capacidades aos recursos de pessoas e processos existentes na empresa para gerar riqueza.

Pennings (1998) e Tidd, Bessant e Pavitt (2005) conceituam três diferentes tipos de inovação: a) inovação de processos aquela que afetam a realização dos processos de produção, desde a matéria-prima até o produto final que engloba a distribuição dos mesmos; b) inovação por posição quando ocorrem mudanças no contexto no qual um produto ou serviço é introduzido e; c) Inovação de paradigma como sendo as mudanças nos modelos mentais subjacentes que moldam o que a organização faz. Com isso, Pennings, Tidd, Bessant e Pavitt conceituam como 
inovação em produtos ou serviços as mudanças de aperfeiçoamento em produtos e serviços oferecidos pelas empresas.

Vemos, então, que a forma de se inovar em serviços é diferente, pois a premissa consiste na inovação de processos, com o uso de novas tecnologias para aumentar a eficiência na entrega de serviços essenciais. É o caso dos primeiros ATM (Automatic Teller Machine) bancários, com operações de saques. Em um segundo estágio, os novos sistemas de entrega de serviços são utilizados para complementar a qualidade, possibilidade e a facilidade de acesso do serviço, como o número de operações que nos dias atuais podem ser realizadas nos ATM. Só em um terceiro ciclo é que os novos produtos decorrentes das novas tecnologias são criados e nesse caso, são exemplos os seguros contra fraude e roubo de cartão eletrônico (ANDREASSI, 2002).

O segmento de serviços vem aumentando significativamente nas duas últimas décadas no Brasil e fatores contribuíram para a mudança desse cenário devido à importância do segmento de serviços para a economia mundial, tanto em países desenvolvidos quanto nos subdesenvolvidos, ao mesmo tempo em que a fabricação de bens decresceu. Os serviços já são dominantes e de acordo com a Organização para a Cooperação e o Desenvolvimento Econômico (OCDE, 2005a) totalizam 70\% da produção agregada e do emprego nos países que fazem parte da OCDE e representam cerca de 75\% da renda nos EUA.

Processos de inovação diferem muito de acordo com o segmento e em termos de desenvolvimento, taxa de mudança tecnológica, interações e acesso ao conhecimento, assim como em termos de estruturas organizacionais e fatores institucionais (MALERBA, 2005). Alguns setores são caracterizados por aceleradas mudanças e inovações radicais, outros por mudanças pontuais e de menor impacto. Sundbo e Gallouj (1998) definem inovação como uma mudança nos negócios pela adição de um novo elemento, ou pela combinação de elementos velhos em um sentido schumpeteriano, porém, implica que a mudança é motivada para ser realizada mais de uma vez.

Ambos definem quatro tipos de inovação em serviços: de produto, de processo, organizacional e de mercado. Como exemplo de inovação organizacional, pode-se citar a introdução da gestão da qualidade total. As inovações de processo são renovações de procedimentos para produzir e entregar o serviço, e podem ser subdivididas em duas categorias: no processo de produção "back office" e no processo de entrega "front office". Inovações de mercado são novos comportamentos mercadológicos, como, por exemplo, encontrar um novo segmento ou nicho de mercado. Com isso sugerem uma outra possível forma de inovação, chamada de $a d$ hoc, a construção socialmente interativa para um problema particular do cliente e pela formalização da experiência deste. Para Drejer (2004) a inovação ad hoc não pode ser considerada como tal, visto que isso equivaleria a dizer que aprendizado, desenvolvimento de competência e codificação de conhecimento correspondem a inovações.

Para a OCDE (2005b), as inovações em serviços têm as seguintes especificidades: (I) dependem menos de investimentos em P\&D formal, e mais de aquisição de conhecimento através da compra de equipamentos, propriedade intelectual, assim como de colaboração; (II) o desenvolvimento de recursos humanos é particularmente importante para os serviços, e a falta de mão de obra especializada pode ser um gargalo para a inovação na maior parte dos países 
da OCDE; (III) empresas menores tendem a ser menos inovativas. Mas o empreendedorismo é um fator que favorece a inovação; (IV) proteção de propriedade intelectual é um tema que merece atenção, especialmente no que diz respeito a softwares e métodos de negócios.

A inovação no segmento de serviços e a sua importância para o crescimento econômico é notória, e com isso direcionou vários estudos sobre inovação em serviços (DE JONG et al., 2003; HAUKNES, 1998; HOWELLS; TETHER, 2004; MILES, 2005). Os principais autores defendem que o segmento de serviços é naturalmente inovador, apesar das inovações apresentarem, em geral, um caráter menos tecnológico comparando-se com os processos produtivos das indústrias. Os estudos do setor defendem a importância das inovações organizacionais, e defendem que o estudo sobre a inovação em serviços pode contribuir para a solução de alguns problemas na indústria, visto que há uma série de atividades de serviços.

O segmento de serviços é em muito variado, Howells e Tether (2004) classificam os serviços em quatro grupos: serviços que lidam sobretudo com produtos (logística), os que trabalham com informação (call centers), serviços baseados em conhecimento, e serviços que lidam com pessoas (saúde). Porém, diversas características são, em geral, iguais e aplicam-se à maioria dos serviços.

O desenvolvimento da sistemática de processos pode ser mais informal para os serviços do que para bens duráveis, com a pesquisa, ideias, viabilidade, seguida pela implementação. Mas tendem a ser um processo contínuo, com mudanças pontuais, ou não, em seus processos.

A inovação pode ser dividida em três níveis que são: 1) descontínuas, ou radical inovação que implica na introdução "produtos novos para o mundo"; tecnologias ou ideias sensivelmente novas, as quais necessitam de qualificações de pessoal, novos processos ou sistemas; 2) sintética - Inovação que não requer tecnologia nova, mas sim, a combinação do conjunto de tecnologias já existentes; 3) Incremental ou Contínua Inovação que introduz melhorias, correções, ou características adicionais a produtos, serviços ou processos.

A inovação em serviços ganha crescente atenção em âmbito internacional, como o projeto Services In Innovation, Innovation in Services - Services in European Innovation Systems (SI4S), patrocinado pela Comunidade Europeia, constatou-se que as maiores empresas tendem a ser mais inovadoras. As empresas que se internacionalizam tendem a ser mais inovadoras, em função do intercâmbio de ideias. A falta de mão de obra competente, de recursos financeiros e de habilidade organizacional são os principais vacos para o processo de inovação. As inovações tendem a ser simples e incrementais, e são facilmente imitáveis por concorrentes atentos a isso. Esse caráter fomento, oposto à inovação em etapas, mais característico da indústria, é desenvolvido por Tether (2004) e Gallouj e Weinstein (1997). Outro exemplo é o projeto Enhacing the Performance of the Service Sector, da OCDE.

As evidências obtidas no que há de mais novo sobre o assunto com constatações de pesquisas anteriores de Cordovil, Xavier e Moreia (2003), Marques e Alcântara (2003) e Monteiro (2007), demonstram que a estratégia de diferenciação embasada na qualidade dos serviços ofertados e relacionados às buscas por ganhos em escala, como o principal diferencial da estratégia adotada pelos supermercados que obtiveram um bom desempenho em seus lucros. 


\subsection{Vantagem Competitiva}

Origens da concepção da vantagem competitiva nos estudos de estratégia empresarial são encontradas em Ansoff (1965), com um sentido diferente dos dias atuais. Ansoff usou a definição em um entendimento mercadológico, para descrever a vantagem derivada para percepções futuras de tendências de mercado à frente dos demais concorrentes e ajustar sua oferta para isto. Nesta definição, a vantagem competitiva possuía similaridade com o conceito atual, porém, tinha um papel secundário no contexto geral da estratégia.

Passados 25 anos, Porter (1990) demonstrou que as empresas bem-sucedidas estavam disciplinadas a padrões definidos de comportamento e propôs uma tipologia composta de três estratégias genéricas: liderança no custo total, diferenciação e enfoque. Segundo ele, as empresas que conseguem maior rentabilidade dentro de são aquelas que criam vantagem competitiva seguindo uma das estratégias comuns.

A estratégia de liderança no custo total é aquela na qual a organização faz com que este custo seja praticado no menor índice possível em relação aos seus demais concorrentes. $\mathrm{O}$ custo mais baixo funciona como um mecanismo de defesa da organização contra os ataques de seus concorrentes, especialmente na questão da guerra de preços. Porter (1990) entende que somente pode existir um único líder em custo, pois, do contrário, a disputa pelas parcelas de mercado entre várias empresas em busca da liderança em custo levaria a uma guerra de preços que resultaria em um fracasso para a estrutura de longo prazo destas empresas no mercado.

A estratégia de diferenciação consiste no oferecimento de um produto que seja considerado único pelos clientes, com características que o distingam daqueles oferecidos pelos demais concorrentes. A diferenciação então se torna um "escudo" contra as forças do ambiente, embora de uma forma distinta daquela permitida pela diferença em custo. Contudo, geram fidelidade e a diminuição da exigência ao preço, isto é, clientes dispostos a pagar mais para terem um produto que eles consideram que melhor atendam às suas necessidades, que blindam a empresa da rivalidade de seus concorrentes. A estratégia de enfoque consiste na capacidade de atender melhor ao seu público alvo estratégico do que aqueles concorrentes que buscam atender a toda a parcela do segmento. Este alvo estratégico deve ser suficientemente limitado, a fim de permitir o atendimento de uma maneira eficaz. $\mathrm{O}$ alvo limitado pode ser atendido por uma posição de custo menor ou por uma diferenciação, mesmo que não seja capaz de manter uma dessas posições em relação ao segmento como um todo.

Na análise de Porter (1990), são as contribuições denominadas como Visão Baseada em Recursos (VBR) (Resource-Based View): durante a década de 1980, o principal foco da análise estratégica foi a correlação entre o ambiente externo, a estratégia e o consequente desempenho das empresas, e, em muito foi desconsiderada a relação entre os recursos e competências da empresa e sua escolha estratégica (CARNEIRO; CAVALCANTI; SILVA, 1997).

Contribuições, que incluem Wernerfelt (1984; 1995), Schmalensee (1985), Barney (1986; 1991), Dierickx com Cool (1989), Rumelt (1991) e Conner (1991), mostram que a influência das características das empresas, sobre suas rentabilidades relativas, é muito mais significativa do que o segmento no qual as empresas pertencem. 
Os mesmos autores analisaram as características necessárias dos recursos para que estes se tornassem uma fonte de vantagem competitiva, a influência das barreiras e diferenças de rentabilidade das empresas, o histórico da empresa na obtenção e desenvolvimento de competências organizacionais examinadas pelas suas escolhas no passado, a importância das diferenças das práticas empresariais para explicar as diferenças de resultados das empresas.

A relevância que trata da importância dos recursos e das características que as organizações devem possuir é apresentada por Barney (1991), que enfatiza que dentre todos os recursos, apenas alguns formarão base para a vantagem competitiva. Em direção a esse potencial, o recurso tem que apresentar quatro atributos: (a) deve ser valioso, para que possa explorar oportunidades e neutralizar ameaças, (b) deve ser raro, representando um diferencial entre a empresa e seus concorrentes, (c) deve ser imperfeitamente imitável, e (d) não pode ter substitutos (BARNEY, 1991; HITT; IRELAND; HOSKINSSON, 2001).

A empresa e a cultura organizacional não são imitáveis (GHEMAWAT, 2000; HUNT, 2000). Além disso, os recursos não devem ser facilmente substituíveis, por vezes, recursos diferentes podem gerar estratégias equivalentes (BARNEY, 1991). Se os recursos e capacidades de uma empresa podem ser facilmente adquiridos pelas suas concorrentes, os mesmos não podem ser considerados fonte de vantagem competitiva (WERNEFELT, 1984). A homogeneidade dos recursos impossibilita que esses gerem diferencial de competição (HITT; IRELAND; HOSKINSSON, 2001).

Wernerfelt (1995) afirma que, em um ambiente altamente competitivo, é difícil que uma empresa tenha sucesso se não tiver uma estratégia baseada em recursos, porque uma empresa estará sempre competindo eternamente contra o melhor, seja qual for seu segmento de atuação.

Cooper e Argyris (2003) mencionam no Dicionário Enciclopédico de Administração, que a Vantagem Competitiva pode ser assegurada por meio de diferenciação da organização e ou de seus produtos e serviços de alguma maneira, para obter a preferência de todo ou de parte do mercado sobre os seus concorrentes. Isso pode resultar em participação de mercado com margens mais altas que os concorrentes. Em geral, vantagem competitiva pode ser obtida pelo oferecimento de maior valor ao cliente. Não há motivo para utilizar o termo vantagem competitiva como competência distinta, com superioridade relativa em habilidades, recursos, ou superioridade de posição no mercado, já que o oferecimento de maior valor ao cliente resulta em alta participação de mercado (COOPER; ARGYRIS, 2003).

Para Peppers (2003), a real vantagem competitiva de uma empresa em ter informação sobre seus clientes que a concorrência não tem, e ser capaz de transformar rapidamente esses dados em negócios, a fim de estabelecer relacionamentos valiosos em seu nicho de mercado. Pode-se dizer que a ligação entre a resolução e os resultados esperados é a utilização da informação dos clientes e mercados, nisto Zenone (2001) menciona que a única coisa que coloca uma organização em vantagem competitiva é a empresa conseguir utilizar esse conhecimento, e principalmente com que velocidade transformará esse conhecimento em algo novo. 


\subsection{O segmento de Supermercados}

Em Rojo (1998), com quase cinco décadas de implantação no Brasil, o supermercado tornou-se um elemento natural da paisagem de qualquer cidade brasileira, e um elemento indissociável do modo de vida do consumidor. Na década de 1960, já era presença marcante em todas as principais cidades brasileiras. A década de 1970 foi o período da grande expansão do setor, com as grandes cadeias em paralelo ao desenvolvimento econômico que no Brasil acontecia. Durante essa década também foram instalados os primeiros hipermercados. $\mathrm{Na}$ capital Paulista o primeiro (um marco) foi da rede francesa Carrefour (ABRAS, 1993).

Na década de 1980, novamente por Rojo (1998), o setor de supermercados já ocupava praticamente todo o país, enfrentando uma forte concorrência. Foi uma década de muitas dificuldades para a maioria dos brasileiros; a rentabilidade do setor começou a diminuir, incorporando relações comerciais mais difíceis com as relações de poder de compra com os fornecedores. Com um clima ainda de incerteza e recessão, o início da década de 1990 foi um período de modificações voltadas principalmente para o aproveitamento mais racional do mercado, desenvolvendo-se tipos de lojas adaptadas às características da população atendida. A concorrência entre os supermercados tornou-se extremamente acirrada, sendo que a disputa pelo mercado ficou ainda mais agressiva. Rojo (1998), classifica as lojas que comercializam alimentos em tradicionais e autosserviço. Ele explica que as lojas de autosserviço são caracterizadas por comercializarem alimentos, exporem a maioria dos produtos de maneira acessível permitindo aos fregueses se auto servirem, disponibilizarem aos clientes carrinhos e cestas e, principalmente, por possuírem qualquer equipamento, que permita a soma conferência das compras. As lojas tradicionais são aquelas nas quais a presença de um vendedor é necessária.

Em pesquisa realizada pela Associação Brasileira de Supermercados (ABRAS), o Estado de São Paulo é o que mais fatura com os supermercados (RANKING ABRAS, 2017). Com esse dado, percebe-se a força significativa do setor supermercadista Paulista. Com isso, as empresas de software enxerguem uma nova oportunidade de negócio, buscam inovar e apresentar novas soluções, para disponibilizar mais alternativas e possibilidades para o segmento oferecer inovação aos clientes que, nos últimos anos, trouxeram a modernização do setor proporcionada pela tecnologia da informação, além de um aperfeiçoamento e uma maior preocupação com a qualidade dos serviços, dentre eles o tempo de espera nas filas para o checkout.

\section{Metodologia}

Além de verificar se há uma relação entre a inovação de serviços e vantagem competitiva nas redes de supermercados da cidade de São Paulo, procurou-se atingir os fatores específicos que inferem nas filas de checkout, e como a inovação em serviços gera benefícios para o setor. Utilizou-se Pesquisa qualitativa, com a coleta de dados e no tratamento destes através da técnica de Análise descritiva.

O caminho percorrido na observação dos sintomas, e abordado para o diagnóstico, foi através da pesquisa qualitativa. Conforme Bogdan e Biklen (1994), esta é elaborada com a obtenção de dados descritivos, coletados com o contato direto do pesquisador com a situação analisada. 
Foi utilizada uma amostra não-probabilística, por conveniência (MALHOTRA, 2001) de 40 supermercados nas quatro zonas da cidade de São Paulo, com a realização das compras em dois supermercados por dia em horários diversificados. A pesquisa transcorreu por 30 dias, entre os meses de fevereiro e março de 2020.

Definido o objeto de estudo, partiu-se para a elaboração do projeto de pesquisa em campo cujo sistema de coleta buscou os dados primários. "Estes são dados que não foram antes coletados, estando ainda em posse dos pesquisados, e que são coletados com o propósito de atender às necessidades específicas da pesquisa em andamento" (MATTAR, 2001).

\section{Análise dos Resultados}

\subsection{Caracterização da amostra}

Para classificar o porte desses supermercados, foi utilizada a classificação da Nielsen (2004) empresa multinacional de pesquisa em marketing que classifica o porte da seguinte forma: de 1 a 4 checkouts pequenos supermercados, de 05 a 09 checkouts médios supermercados, de 10 a 19 checkouts grandes supermercados e acima de 20 checkouts os hipermercados. Foi então delimitado de 05 a 09 checkouts médios supermercados.

A amostra foi feita em: 10 supermercados nas zonas: Sul; 10 Norte; 10; Leste e 10 na Oeste da cidade de São Paulo. Como parâmetro para aferição do tempo de espera nas filas, foram feitas compras de menos de 10 itens de consumo nos horários de maior movimento (de segunda à sexta-feira) das 17:00 às 20:00 horas. Com relação ao tempo de espera, na zona Sul, o tempo foi de 9,3 minutos; na zona Norte 6,8 minutos; na zona Leste 10,2 minutos e na zona Oeste 4,5 minutos. A tabela abaixo apresenta o tempo de espera nas filas:

Tabela 1. Tempo esperado/filas de checkout

\begin{tabular}{ll}
\hline Zona & Tempo de espera na fila \\
\hline \multirow{2}{*}{ Sul } & 1- 9 min.; 2- 11 min.; 3- 8 min.; 4- 5 min.; 5- 8 min.; 6- 12 min.; 7- 14 min.; 8- 11 min.; \\
& 9- 9 min.; 10- 6 min. \\
Norte & 1- 5 min.; 2- 13 min.; 3- 7 min.; 4- 8 min.; 5-10- min.; 6- 3 min.; 7- 7 min.; 8- 1 min.; 9- 6 min.; \\
& 10- 8 min. \\
Leste & 1- 9 min.; 2- 8 min.; 3- 18 min.; 4- 8 min.; 5- 7 min.; 6- 11 min.; 7- 17 min.; 8- 8 min.; 9- 7 min.; \\
& 10- 9 min. \\
Oeste & 1- 2 min.; 2- 5 min.; 3- 4 min.; 4- 3 min.; 5- 10 min.; 6- 5 min.; 7- 4 min.; 8- 2 min.; 9- 3 min.; \\
& 10- 7 min. \\
& Obs: 1 - 10 $=$ Supermercados visitados por zona
\end{tabular}

Fonte: Autoria própria. 


\subsection{Inovação em serviços}

Em relação à inovação em serviços oferecidos, foram observados em campo e com a interação com o ambiente: o tempo de espera na fila para o checkout, com uso de Análise descritiva (estatísticas descritivas) e com isso, foram encontrados 3 fatores: stress, tempo e desistência.

Tabela 2. Aspectos detectados e observados na etapa da fila

\begin{tabular}{lccc}
\hline Fatores detectados & Stress & Tempo & Desistência \\
\hline Reclamações diversas verbais dos clientes & $15 \%$ & & \\
Reclamação de maior tempo na fila do que para pegar os produtos & & $8 \%$ & \\
Reclamação da fila, caixas ociosos, lentos e vazios & & $11 \%$ \\
\hline
\end{tabular}

Fonte: Autoria própria.

\subsection{Vantagem Competitiva}

Também foi observado o contexto em relação à vantagem competitiva no segmento de supermercados e constatado, com o uso de Análise estatística descritiva, como o principal fator: a desistência da compra pelo cliente diante da demora na fila do checkout.

Tabela 3. Dano causado e perda da vantagem competitiva

\begin{tabular}{lc}
\hline Fator & Percentual \\
\hline Clientes que desistem da compra devido a fila de checkout. & $\mathbf{1 1 \%}$ \\
\hline
\end{tabular}

Fonte: Autoria própria.

Fialho (2016) explica que: toda vez que um cliente passa suas compras pelos terminais de frente de caixa, todo o investimento realizado (em compras de mercadorias, logística, armazenagem etc.) é transformado em dinheiro. Assim, o objetivo maior, que é a venda, é concretizado. Com esta devida importância, falhas provenientes na etapa de checkout necessitam da devida atenção por parte da administração do supermercado.

\section{Considerações Finais}

O principal objetivo desta pesquisa foi verificar se há uma relação entre a inovação na etapa de checkout e a vantagem competitiva nas redes de supermercados na cidade de São Paulo. Para tanto, foi realizada uma revisão teórica sobre os conceitos de inovação em serviços e vantagem competitiva. Após a escolha da metodologia, aplicou-se a Pesquisa qualitativa, com a técnica de observação para a coleta de dados e de Análise descritiva. 
Com os resultados obtidos, é possível denotar que, na realização da investigação, o serviço de checkout e a forma como é feito influem na escolha de concluir a compra ou não. Além disso, eles explicam os $11 \%$ resultados do índice de desistência, quando analisada a parte referente à inovação. Em relação à vantagem competitiva, elementos de stress, tempo de espera, tamanho da fila concluem os outros $100 \%$ dos fatores da amostra constatada.

As evidências, obtidas no que há de mais novo sobre o assunto com constatações de pesquisas anteriores de Cordovil, Xavier e Moreia (2003), Marques e Alcântara (2003), e Monteiro (2007), apontam que a estratégia de diferenciação embasada na qualidade dos serviços ofertados e relacionados às buscas por ganhos em escala, são uma valiosa estratégia adotada pelos supermercados que obtiveram um bom desempenho em seus lucros.

É possível concluir que há uma relação entre inovação de serviços e a vantagem competitiva, e com esta pesquisa, identificou-se que um dos elementos geradores de vantagem competitiva para os supermercados é um eficaz sistema de checkout para o cliente. As inovações de serviços, por exemplo, a praticidade, rapidez no pagamento do produto ao cliente, só acontece pelo fato de haver tecnologias eficientes, como citados na revisão de literatura.

\section{Conclusão}

Um grande fator ao desenvolvimento de sistemas automatizados foi propiciado pelo uso do código de barras devido à agilidade de entrada de dados, que é uma parte do processo automatizado (SOARES, 1991). Esta utilização nos supermercados, proporcionou algumas vantagens como redução nos custos, controle das mercadorias, além da redução do tempo de espera para o checkout, fato o que proporcionou grande satisfação aos clientes. Da mesma forma como esta tecnologia trouxe consigo uma grande eficácia, novas tecnologias se fazem necessárias, e são cada vez mais cobradas por clientes de supermercados, que não desejam mais o stress ocasionado pelas filas e demoras na etapa de checkout.

Infere como limitação deste estudo, a pequena amostra geográfica utilizada para a realização da pesquisa, decorrentes da escolha do tipo de amostra não probabilística, por conveniência que não permite generalização dos resultados da pesquisa.

A pesquisa traz contribuições acadêmicas e gerenciais à medida que permitirá a ampliação do conhecimento sobre a relação entre a inovação em serviços e a vantagem competitiva no segmento de supermercados da capital paulista. Para estas empresas, o estudo traz indicações do que os consumidores pensam e valorizam sobre a decisão na hora de escolherem entrar em um supermercado para fazerem pequenas compras. Assim sendo, os dados poderão auxiliar os profissionais das áreas de operações e serviços do referido setor na formulação de estratégias de melhorias deste segmento de grande importância aos consumidores.

Como um pequeno ensaio realizado, a pesquisa tem potencial em ser um futuro pano de fundo para outra pesquisa, em uma amostra maior, para se verificar diferenças relevantes, com um trabalho que utilize a Metodologia qualitativa e que traga em sua abordagem desde o desenvolvimento da inovação, sua difusão dentro do setor de supermercados, a fim de motivar a devida importância no segmento deste fator gerador de vantagem competitiva. 


\section{Referências}

NIELSEN, A. C. Quinto estatuto anual de marcas próprias. São Paulo: Nielsen, 2004.

ANDREASSI, Tales. Por que é tão difícil inovar em serviços? Gazeta Mercantil, São Paulo, ed. 11, 12 e 13 de janeiro, 2002.

ANSOFF, H. I. Corporate Strategy. Harmondsworth: Penguin. 1965 ANSOFF, H. I. Strategic management. New York: Wiley, 1979.

ASSOCIAÇÃO BRASILEIRA DE SUPERMERCADOS - ABRAS. 40 Anos de supermercados no Brasil. São Paulo, 1993.

ASSOCIAÇÃO PAULISTA DE SUPERMERCADOS - APAS. APAS Show apresenta grande novidade na busca por solucionar problemas comuns a supermercados e consumidores. Disponível em: https://portalapas.org. br/apas-show-apresenta-grande-novidade-na-busca-por-solucionar-problemas-comuns-supermercados-econsumidores/. Acesso em: 19 mai 2020.

ASSOCIAÇÃO PAULISTA DE SUPERMERCADOS - APAS. Pesquisa “Tendências do Consumidor em Supermercados 2018/2019". Disponível em: https://portalapas.org.br/consumidor-dos-supermercados-jachegou-na-era-omni-channel-revela-pesquisa-da-apas/. Acesso em: 30 abril 2019.

BARNEY, JAY. Firm resources and sustained competitive advantage. Journal of management, v. 17, n. 1, 1991.

BOGDAN, Roberto C.; BIKLEN, Sari Knopp. Investigação qualitativa em educação. Porto: Porto Editora, 1994.

CARNEIRO, J. M. T.; CAVALCANTI, M. A. F. D.; SILVA, J. F. DA. Porter revisitado: análise crítica da tipologia estratégica do mestre. Revista de Administração Contemporânea, v. 1, n. 3, p. 7-30, 2017.

CONNER, K. R. A Historical Comparison of Resource-based Theory and Five Schools of Thought within Industrial Organization Economics: Do We Have a New Theory of the Firm? Journal of Management, v. 17, n. 1, 1991.

COOPER, Cary L.; ARGYRIS, Chris. Dicionário Enciclopédico de Administração, São Paulo: Atlas, 2003.

CORDOVIL, Domingos et al. (coords.). Varejo Competitivo: São Paulo: Atlas, v. 7, 2003.

CYRILLO, D.C. O papel dos supermercados no varejo de alimentos. São Paulo: Instituto de Pesquisas Econômicas, 1987.

DIERICKX, Ingemar; COOL, Karel. Asset stock accumulation and sustainability of competitive advantage. Management Science, v. 35, n. 12, 1989.

DREJER, I. Identifying innovation in surveys of services: a Schumpeterian perspective. Research Policy, v. 33, p. 51-562, 2004.

DRUCKER, Peter Ferdinand. Inovação e Espírito Empreendedor (entrepreneurship): prática e princípios. São Paulo: Pioneira, 1987.

FIALHO, Márcio. Você reconhece a real importância de sua Frente de Caixa? Disponível em: http://devitecnologia. blogspot.com.br/2016/05/voce-reconhece-real-importancia-de-sua.html. Acesso em: 19 jul 2020.

GALLOUJ, F; WEINSTEIN, O. Innovation in services. Research Policy, v. 26, p. 537-556, 1997.

GHEMAWAT, PANKAJ. A estratégia e o cenário dos negócios. Porto Alegre: Editora Bookman, 2000.

HITT, MICHAEL A. et. al. Administração Estratégica. São Paulo: Thonson, 2001. 
HUNT, SHELBY D. A general theory of competition. London, Sage Publications, 2000. HAUKNES, J. Services in Innovation, Innovation in Services. Oslo: SI4S Final Report, STEP Group, 1998.

HOWELLS, J. R. L.; TETHER, B. S. Innovation in Services: Issues at Stake and Trends - A Report for the European Commission. INNO-Studies 2001: Lot 3 (ENTR-C/2001), Brussels. de Jong, J.P.J., A. Bruins, W. Dolfsma e J. Meijaard (2003). Innovation in Services Firms Explored: What, How and Why? Zoetermeer: EIM Report, 2004.

MALHOTRA, Naresh K. Pesquisa de Marketing: uma orientação aplicada. Porto Alegre: Bookman, 2001.

MALERBA, F. Sectoral Systems: How and Why Innovation Differs Across Sectors. Chapter 14. In: FAGERBERG, J.; MOWERY, D.; NELSON, R.R. (eds.). The Oxford Handbook of Innovation. Oxford: Oxford University Press, 2005.

MATTAR, Fause. Pesquisa de Marketing. São Paulo: Atlas, 2001.

MILES, I. Innovation in Services. Chapter 16. In: FAGERBERG, J., et. al (eds.). The Oxford Handbook of Innovation. Oxford: Oxford University Press, 2015.

NCR CORPORATION. Self-Checkount: a global consumer perspective. NCR Corporation, Georgia, p. 1-18, 2014. Disponível em: https://www.ncr.com/sites/default/files/white_papers/RET_SCO_wp.pdf. Acesso em: 20 jul 2020.

NISCZAK, Priscila M. Teoria das Filas e Simulações aplicadas a caixas de autoatendimento e caixas-rápidos de um supermercado, 2015. Trabalho de conclusão de Curso (Graduação) - Curso de Engenharia de Produção. Universidade Estadual de Maringá, 2015.

PAINEL LOGÍSTICO. Revista e Portal Especializado em Logística. Disponível em: http://www.painellogistico. com.br/tecnologia-inteligente-e-o-futuro-da-industria-que-atende-o-comerciointernacional/. Acesso em: 08 jul 2020.

OECD. Promoting innovation in services. Paris: OECD. DSTI/STP/TIP (2004)4/FINAL. 14 Oct, 2005a.

Oslo manual: guidelines for collecting and interpreting innovation data. Paris: OECD, 2005b.

PAVITT, Keith. Sectorial paterns of technical change: towards a taxonomy and a theory. Research Policy, v. 13, 1984.

PENNINGS, J. Innovations as Precursors of Organizational Performance, no Information Technology and Organizational Transformation: Innovation for the $21^{\text {st }}$ Century Organization. In: GALLIERS, R. D. e BAETS, W. R. J. (orgs.). Chichester: John Wiley \& Sons, 1998.

PORTER, Michael E. Vantagem competitiva das nações, Campus, Rio de Janeiro, 1990.

PORTER, Michael. Vantagem competitiva: criando e sustentando um desempenho superior. Rio de Janeiro: Campus, 1990.

RANKING ABRAS. A distribuição da força do setor pelo Brasil. Abrasnet, 2017. Disponível em: http://www. abrasnet.com.br/economia-e-pesquisa/ranking-abras/regionais/. Acesso em: 22 jul 2020.

RUMELT, Richard P. How much does industry matter? Strategic Management Journal, v.12, p.167-85, 1991.

ROJO, F. Supermercados no Brasil. São Paulo: Atlas, 1998.

SCHMALENSEE, Richard. Do markets differ much?. American Economic Review, v. 75, n. 3, 1985.

SOARES, A. Código de barras: a presença visível da automação. Revista de Administração de Empresas, São Paulo, v. 31, n. 1, 1991. 
SUNDBO, J.; GALLOUJ, F. Innovation in services. SI4S Synthesis Paper (S2). 1998.

TIDD, Joe; BESSANT, John; PAVITT, Keith. Managing Innovation: Integrating Technological, Market and Organizational Change. Chinchester: John Wiley \& Sons, 2005.

ZENONE, Luís Carlos. CRM: conceitos e estratégias. São Paulo: Atlas, 2001.

WERNEFELT, Birger. A resource- based view of the firm. Strategic Management Journal, v. 5, 1984. 1995.

. A resource-based view of the firm: tem years after. Strategic Management Journal, v. 16, p. 171-174,

RECEBIDO: 19 DE JANEIRO DE 2021. APROVADO: 21 DE FEVEREIRO DE 2021. 